\title{
Study of CT Variations in Patients with Chronic Rhinosinusitis at Rural based Tertiary Care Hospital
}

\author{
Ajay Kamble ${ }^{1}$, Deepika Garg ${ }^{2}$, Manish Puttewar ${ }^{3}$ \\ ${ }^{1}$ Assistant Professor, ENT-HNS, GMC, Chandrapur, ${ }^{2}$ Associate Professor, ENT-HNS, MGIMS, Sewagram, ${ }^{3}$ Ex Prof at MGIMS, \\ Department of ENT - HNS, Presently Consultant Surgeon, Alexis Hospital, India
}

Corresponding author: Dr Deepika Garg, Associate Professor - ENT \& HNS, MGIMS Sewagram Wardha 442102, India

DOI: http://dx.doi.org/10.21276/ijcmsr.2019.4.3.45

How to cite this article: Ajay Kamble, Deepika Garg, Manish Puttewar. Study of CT variations in patients with chronic rhinosinusitis at rural based tertiary care hospital. International Journal of Contemporary Medicine Surgery and Radiology. 2019;4(3):C207-C212.

\section{A B S T R A C T}

Introduction: Chronic Rhinosinusitis is a heterogenous entity with a number of contributing factors. Anatomical Variations of paranasal sinuses are one of them. CT-scan paranasal Sinuses can be a useful tool in the study of these variations and also in providing a roadmap for endoscopic sinus surgery. Current research aimed to study the anatomical variations in sinonasal area by CT scan paranasal sinuses and to correlate these anatomical variations with chronic rhinosinusitis (CRS).

Material and Methods: In this study, 94 patients of CRS, who were refractory to medical treatment for more than 3 months, underwent CT scan paranasal sinus axial and coronal view with axial and coronal views, prior to functional endoscopic sinus surgery. All their information related to clinical findings, investigations was recorded in data sheets and was kept confidential. Scoring of sinus disease was done by Lund \& Mackay Scoring System.

Results: The most common anatomical variations were Deviated nasal septum (64.89\%), concha bullosa (29.74\%) and agger nasi cells (13.83\%). Maxillary Sinus was the most commonly involved sinus (40.4\%).

Conclusion: After evaluation of the results obtained, we postulate that anatomical variations may increase the risk of mucosal disease of paranasal sinuses. We therefore, emphasize that CT scan paranasal sinus in patients with persistent symptoms of CRS for diagnosis and preoperative evaluation can be considered as an important investigation where appropriate to aid the clinical and endoscopic examination findings. This will help to facilitate safe and effective endoscopic sinus surgery.

Keywords: Chronic Rhinosinusitis, Anatomical Variations, CT Scan Paranasal Sinuses

\section{INTRODUCTION}

The term chronic rhinosinusitis (CRS) is defined as a group of disorders characterized by inflammation of the mucosa of nose \& paranasal sinuses of at least 12 consecutive weeks duration. ${ }^{1}$

Functional endoscopic sinus surgery (FESS) has become the surgical treatment of choice in many patients with CRS refractory to medical treatment. This has led to CT scanning becoming the imaging modality of choice as it provides initial screening, helps in surgical planning and provides the surgeon with an operative "roadmap". ${ }^{2}$

The most feared complications of endoscopic sinus surgery are the result of an uncontrolled maneuvering beyond the boundaries of the sinuses. These complications are facilitated by some preexisting anatomical variants or pathological modifications caused by the underlying disease. Understanding the normal anatomy and variations of the paranasal sinuses and Osteomeatal complex (OMC) is therefore the most important prerequisite for FESS. Major anatomic variants leading to OMC obstruction are deviated nasal septum, concha bullosa, paradoxical middle turbinate and infra orbital (Haller) cell. ${ }^{3}$ The aim of this study was to study these anatomic variations of Paranasal sinuses \&
$\mathrm{OMC}$ and their role in the etiology of CRS.

\section{MATERIAL AND METHODS}

Local institution ethical committee approval was taken for the study. Ninety-four patients of CRS attending Otorhinolaryngology \& Head Neck Surgery OPD since $1^{\text {st }}$ August 2010 to $31^{\text {st }}$ September 2012 and who voluntarily consented and met the following eligibility criterion to be part of the study were included in the present study.

\section{Inclusion criteria}

1. Patients with history of running of nose for more than 12 weeks

2. Age above 18 years

3. Written informed consent of the patient

4. Patients who were refractory to medical treatment for more than 3 months.

\section{Exclusion criteria}

1. Age less than 18 years

2. History of previous nasal or sinus surgery

3. Acute rhinosinusistis

4. Malignancies, Diabetes, Tuberculosis

5. Pregnancy, lactation

6. Patients who are not willing for participate in study 
This was followed by detailed ear, nose, throat (ENT) examination. In nasal examination, external, anterior rhinoscopy and posterior rhinoscopy, paranasal sinus and functional [Gertner's plate for airway patency ] examination was carried out. Clinical diagnosis of chronic rhinosinusitis was arrived. X ray PNS water's view and nasal endoscopic examination was done apart from routine investigations.

The patients were subjected for CT scan of paranasal sinuses, Plain (without contrast) with axial and coronal views, prior to functional endoscopic sinus surgery. All their information related to clinical findings, investigations was recorded in

\begin{tabular}{|l|c|c|}
\hline Pattern of sinus involvement & $\begin{array}{c}\text { No. of } \\
\text { patients } \\
\text { (n=94) }\end{array}$ & $\%$ \\
\hline Maxillary alone (M) & 38 & $40.4 \%$ \\
\hline Maxillary + frontal (M+F) & 22 & $23.4 \%$ \\
\hline Maxilary + Ethmoids (M + E) & 14 & $14.8 \%$ \\
\hline Pansinusitis & 9 & $9.5 \%$ \\
\hline Ethmoids alone (E) & 4 & $4.2 \%$ \\
\hline Maxillary + Ethmoids + Frontal (M + E + F) & 3 & $3.1 \%$ \\
\hline Maxillary + sphenoid (M + S) & 2 & $2.1 \%$ \\
\hline Ethmoid + frontal + sphenoid (E + F + S) & 1 & $1.0 \%$ \\
\hline Ethmoid + sphenoid (E + S) & 1 & $1.0 \%$ \\
\hline n= number of patients, M-maxillary, F-frontal, E-ethmoid, \\
\hline S-sphenoid & \multicolumn{2}{|c|}{} \\
\hline Table-1: Pattern of sinus involvement in CRS based on CTscan \\
\hline
\end{tabular}

\begin{tabular}{|l|c|}
\hline L \& M Scoring & No.of patients (percentage) \\
\hline 1 to 5 & $46(38.29 \%)$ \\
\hline 6 to 10 & $26(27.65 \%)$ \\
\hline 11 to 15 & $10(10.63 \%)$ \\
\hline 16 to 20 & $7(7.44 \%)$ \\
\hline 21 to 25 & $5(5.31 \%)$ \\
\hline Total & 94 \\
\hline Mean L \& M score & 7.93 \\
\hline L \& M scoring-Lund and Mackay scoring \\
\hline \multicolumn{2}{|c|}{ Table-2: Distribution of patients according Lund and Mackay } \\
CT-Scoring \\
\hline
\end{tabular}

data sheets and was kept confidential.

CT scan was carried out to see the status of sinuses and to study predisposing anatomical variants. Scoring of sinus disease was done by Lund \& Mackay Scoring System in which all the paranasal sinuses are scored from $0-2$ i.e 0 - no opacification, 1- partial opacification and 2- total opacification of sinuses. In addition, osteomeatal complex was graded as 1- no obstruction and 2- total obstruction. Score on both sides is totaled (maximum score in this staging system is 24$){ }^{4}$

\section{STATISTICAL ANALYSIS}

The analysis was performed using descriptive statistics and inferential statistics using Chi-square test, student paired and unpaired t-test and the SPSS for windows, version 17, Graph pad prism 5.0. Data were expressed as mean and SD. $P$ value $<0.05$ were considered significant.

\section{RESULTS}

\section{Pattern of sinus involvement based on CT scan}

In our study, maxillary sinuses alone were commonly involved in $38(61 \%)$ patients followed by combination of maxillary \& frontal sinus involvement in $22(23.4 \%)$.

Maxillary \& ethmoid sinuses involvement was seen in 14 (14.8\%), pansinusitis in $9(9.5 \%)$ patients and ethmoid sinus alone involvement was seen in 4 (3.1\%).

Other combinations of sinus involvement are seen below in Table I, Graph I.

\section{Lund and Mackay CT-Scoring}

In the present study, maximum number of patients i.e. 46(38.29\%) had Lund \& Mackay CT-scoring between 1 to 5 . This was followed by $26(27.65 \%)$ patients who had CT-score between 6 to 10.10 patients $(10.63 \%)$ had score between 11 to 15,7 patients (7.44\%) had score between 16 to 20 and rest of 5 patients (5.31\%) had score between 21 to 25. The mean Lund \& Mackay CT score in the study was 7.93 (Table 2)

\section{Anatomical variations in CRS seen in CT Paranasal Sinus (n=94)}

In this study, most common anatomical variation was

\begin{tabular}{|c|c|c|}
\hline Anatomical variations & No. of subjects & Percentage (\%) \\
\hline \multirow[t]{2}{*}{ 1.DNS } & 61 & $64.89 \%$ \\
\hline & $\begin{array}{c}\text { Grade I - } 20 \\
\text { Grade II-35 } \\
\text { Grade III - } 2 \\
\text { S-shaped DNS -4 }\end{array}$ & $\begin{array}{l}32.7 \% \\
57.3 \% \\
3.2 \% \\
6.5 \%\end{array}$ \\
\hline \multirow[t]{2}{*}{ 2.concha bullosa } & 28 & $29.74 \%$ \\
\hline & $\begin{array}{c}\text { Unilateral - } 17 \\
\text { Bilateral - } 11\end{array}$ & $\begin{array}{l}60.7 \% \\
39.2 \%\end{array}$ \\
\hline 3.Agger nasi cells & 13 & $13.83 \%$ \\
\hline 4.Paradoxical middle turbinate (PMT) & 4 & $4.26 \%$ \\
\hline 5.Pneumatised vomer & 4 & $4.26 \%$ \\
\hline 6.Onodi cells & 3 & $3.19 \%$ \\
\hline 7.Enlarged ethmoidal bulla & 3 & $3.19 \%$ \\
\hline 8. Haller cells & 2 & $2.13 \%$ \\
\hline 9.Septate maxillary sinus & 1 & $1.06 \%$ \\
\hline
\end{tabular}




\begin{tabular}{|c|c|c|}
\hline Olfactory Fossa depth (mm) & No of patients $(n=94)$ & Percentage (\%) \\
\hline Grade I (1-3mm) & 39 & $41.5 \%$ \\
\hline Grade II (4-7 mm) & 50 & $53.2 \%$ \\
\hline Grade III (8 mm \& more) & 5 & $5.3 \%$ \\
\hline Total & 94 & $100 \%$ \\
\hline \multicolumn{3}{|l|}{ mm-millimeter } \\
\hline
\end{tabular}

\begin{tabular}{|l|c|c|c|c|c|c|}
\hline \multirow{2}{*}{ Author } & \multirow{2}{*}{ Year } & \multicolumn{5}{|c|}{ Sinuses involved in CRS } \\
\cline { 3 - 7 } & & Maxillary & Ethmoids & Frontal & Sphenoid & Pansinusitis \\
\hline A A Ameri et al $^{5}$ & 2005 & $61.9 \%$ & $27.6 \%$ & $18.2 \%$ & $21.2 \%$ & $13.7 \%$ \\
\hline Present study & 2012 & $48.88 \%$ & $19.44 \%$ & $19.44 \%$ & $7.22 \%$ & $9.5 \%$ \\
\hline \multicolumn{7}{|r|}{ Pattern of sinus involvement in CRS in other studies } \\
\hline
\end{tabular}

\begin{tabular}{|l|c|c|}
\hline Author & Year & Pre-treatment mean L \& M score \\
\hline H. Moghaddasi et al $^{7}$ & 2009 & 18.5 \\
\hline Jiann-Jy Chen et al & \\
\hline Present study & 2011 & 8.7 \\
\hline \multicolumn{2}{|c|}{ Lund \& Mackay CT score in various CRS studies } \\
\hline
\end{tabular}

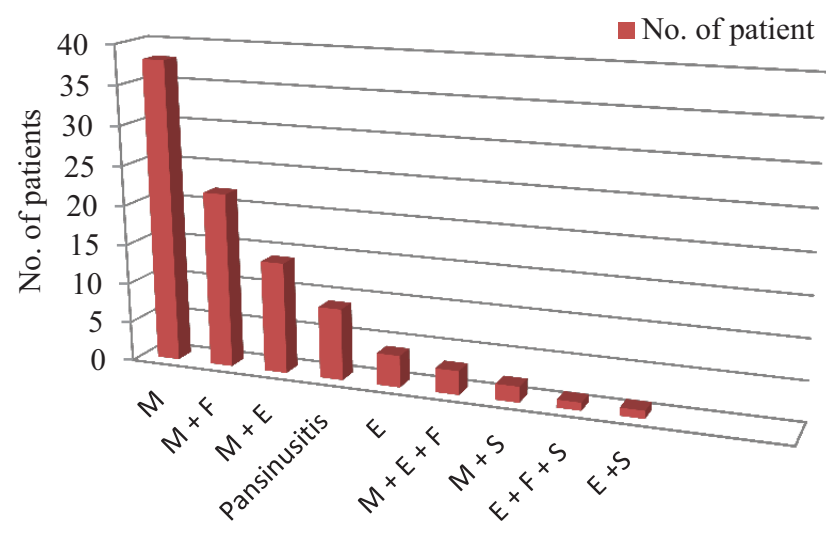

Sinus involvement

(M-maxillary, F-frontal, E-ethmoid, S-sphenoid)

Graph-1: pattern of sinus involvement

deviated nasal septum (DNS) which was seen in 61(64.8 \%) patients. On Cottle's grading for DNS, 20(32.7 \%) had Cottle's grade I deviation i.e. only mild deviation with no obstruction, 35(57.3\%) had grade II deviation i.e. septum was touching the lateral nasal wall but after vasoconstriction there was a gap between the two. There were 2(3.2\%) subjects who had grade III deviation i.e. septum was impacted over the lateral nasal wall. There were $4(6.5 \%)$ patients who had S-shaped DNS.

The second most common anatomical variation was concha bullosa which was seen in 28 (29.7\%) patients. The unilateral concha bullosa seen in 17 (60.7\%), and bilateral concha bullosa seen in 11 (39.2\%) patients.

The agger nasi cells seen in 13(13.8\%), paradoxical middle turbinate in $4(4.2 \%)$, pneumatised vomer in $4(4.2 \%)$, onodi cells in 3(3.1\%), Enlarged ethmoidal bulla in 3(3.19\%), Haller cells in 2(2.1\%), septate maxillary sinus in 1(1.0\%). Depth of Olfactory fossa was also calculated according to Kero's classification (Keros P, 1962) after CTscan. It was found that $39(41.5 \%)$ patients had depth in range of $1-3 \mathrm{~mm}$ i.e Grade I, 50 (53.2\%) had depth from 4-7mm i.e. Grade II and 5 (5.3\%) patients had depth $\geq 8 \mathrm{~mm}$ i.e. Grade III. (Table III $a$ and III $b$ )

\section{DISCUSSION}

The study was carried out in patients of chronic rhinosinusitis (CRS), presenting in the Department of Otorhinolaryngology and Head Neck Surgery, to study anatomical variations in CRS patients.

\section{Pattern of sinus involvement seen in CT Paranasal Sinus}

In our study, maxillary sinuses involvement alone was most common i.e. 38 (61\%) patients whereas maxillary with sphenoid sinus involvement was the least common i.e. 2 (2.1\%) patients. A case-control study was carried out on 148 patients by A A Ameri et al (2005) with a clinical diagnosis of chronic sinusitis who were referred for a sinus CT scan by ENT specialists. They concluded the pattern of sinus involvement as maxillary sinus in $61.9 \%$, ethmoids in $27.6 \%$, frontal sinus in $18.2 \%$, sphenoid in $21.2 \%$ and pansinusitis in $13.7 \% .^{5}$

\section{Lund and Mackay CT- staging in CRS}

In the present study, maximum number of patients i.e. 36(38.29\%) had Lund \& Mackay CT-scoring between 1 to 5 with the mean Land \& Mackay CT score being 7.93 which correlates with study of Jiann-Jy Chen et al. ${ }^{6}$

In another study of $\mathrm{H}$. Moghaddasi et al. the mean Land \& Mackay CT score was 18.5.

Anatomical variations in CRS seen in CT Paranasal Sinus In the present study, most common anatomical variation was deviated nasal septum (DNS) which was seen in $61(64.8 \%)$ patients and concha bullosa which was seen in 28 (29.7\%) patients was second most common.

In the study of Lanza DC et al., the major anatomic variants leading to osteomeatal obstruction are deviated nasal septum, concha bullosa, paradoxical middle turbinate and infra orbital (Haller) cell. ${ }^{3}$ 


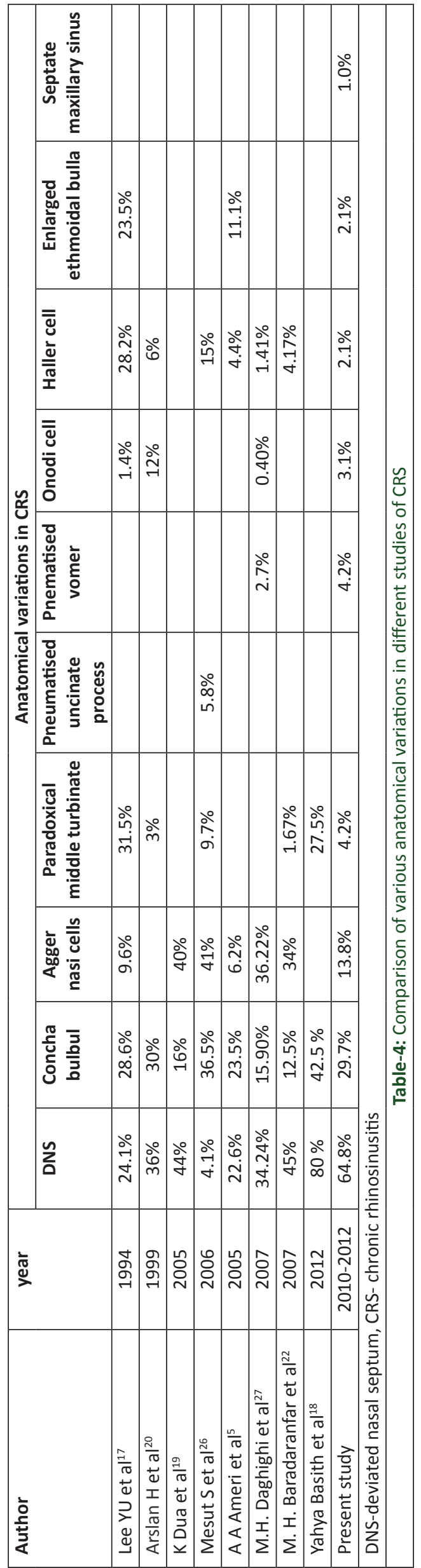

Septal deviation is a common finding and its role in the pathogenesis of chronic rhinosinusitis remains uncertain as reported by Collet et al. ${ }^{8}$ Gray reported a prevalence of bilateral nasal septal deviation in $27 \%$ and unilateral in 31\% from a series of 2380 infants. ${ }^{9}$ Van der Veken showed that the prevalence of septal deviation in children increases from $16 \%$ to $72 \%$ in a linear fashion from 3 to 14 years of age. ${ }^{10}$

Among a cohort of 2112 adults, Gray reported a septal deviation rate of $79 \%{ }^{9}$

In radiological studies relating to CRS, lower prevalence rates of septal deviation are reported with Calhoun finding septal deviation in $19.5 \%$ and Jones in $24 \%$ of control populations. $^{11,12}$

Calhoun, Yousem, Elahi, Elahi and Frenkeil ${ }^{\mathrm{xv}}$ reported a higher incidence and severity of sinus disease with increasing septal deviation in the region of the ostiomeatal complex (OMC) as assessed by CT scan. . $^{11,13,14,15}$

Danese found an association between septal ridges and spurs and ipsilateral sinus disease as assessed by CT scan. ${ }^{16}$

Lee YU et al conducted a study to illustrate frequently encountered anatomic variations on paranasal sinus computed tomography (PNS CT) and to assess their clinical significance. The CT findings of 1523 patients, who underwent PNS CT with no history of sinus surgery, were reviewed, and prevalence of each anatomic variation and its relationship with mucociliary clearance pathway was evaluated. The anatomic variations were encountered such as concha bullosa(28.6\%), paradoxical middle turbinate $(31.5 \%)$, of the uncinate process, such as medially bent or folded(36.3\%), laterally bent $(3.7 \%)$ or uncinate bulla $(0.5 \%)$, Haller's cell (28.2\%), large agger nasi cell (9.6\%) or large ethmoidal bulla(23.5\%), nasal septal deviation(24.1\%) and Onodi ce11(1.4\%). ${ }^{17}$

Yahya Basith conducted a case series study based on radiological assessment to assess the role of anatomical obstruction in the pathogenesis of chronic sinusitis. Anatomical obstruction due to deviated nasal septum, concha bullosa, and paradoxical middle turbinate are included in the study. The results obtained were deviated nasal septum in $80 \%$ cases, concha bullosa in $42.5 \%$ cases and paradoxical middle turbinate in $27.5 \%$ cases. They concluded that most of the cases of chronic sinusitis caused by anatomical obstruction in the nose are found to be due to a deviated nasal septum leading to obstruction of osteomeatal complex. Other major causes are concha bullosa and paradoxical middle turbinate. ${ }^{18}$ In the study of K Dua et al (2005), fifty patients of chronic sinusitis were evaluated by CT Scan PNS - coronal and axial views. The anatomical variations and changes in osteomeatal complex on CT scan were studied. In majority of patients, osteomeatal complex and anterior ethmoids were involved (88\%). Agger nasi cells (40\%) were the most common anatomical variations followed by concha bullosa and haller cells (16\%). Apart from this deviated nasal septum was found in $44 \%$ of patients. The variations found on CT scan were later confirmed on nasal endoscopy. All the patients then underwent endoscopic sinus surgery. This study revealed various anatomical variations which were responsible for the primary pathology of the patient. ${ }^{19}$

Arslan H et al (1999) conducted a study with the aims to show the main anatomical variations in the ostiomeatal 
complex and paranasal sinuses which are usually depicted by computed tomography (CT). CT scans obtained with $2 \mathrm{~mm}$ thicknesses in axial and coronal plane from a series of 200 patients with chronic sinusitis were examined to determine the prevalence of anatomic variants. Anatomical variations determined were supraorbital recess in 6\%, concha bullosa in $30 \%$, sphenomaxillary plate in $17 \%$, infra-orbital ethmoid cells (Haller's cells) in 6\%, spheno-ethmoid cells (Onodi's cells) in $12 \%$, pneumatization of the anterior clinoid process in $6 \%$, carotid artery bulging into the sphenoid sinus in $8 \%$, pneumatization of the uncinate process in $2 \%$, paradoxical curvature of the middle turbinate in $3 \%$ and septal deviation in $36 \% .^{20}$

In the study of M. H. Baradaranfar (2007) on anatomic variations of paranasal sinuses, total of 120 patients were included. They found Agger Nasi cells in 43(36\%), Haller cells in $5(4.17 \%)$, concha bullosa in $15(12.5 \%)$, paradoxical middle turbinate in $2(1.67 \%)$ and septal deviation in 54 patients $(45 \%) .^{21}$

In a study by Scribano et al from Italy, $59 \%$ of their patients with chronic sinusitis had concha bullosa and $5 \%$ of them had large ethmoidal bulla. The remarkable difference between the prevalence of these variants among their patients as compared with the normal population lead to the conclusion that these anatomic changes probably increase the risk of sinus inflammatory diseases by bringing the mucosal lining of the osteomeatal unit in contact with the mucosal lining of the paranasal sinuses. ${ }^{22}$

Also in a Swiss study, S-Nadas et al. reported that 35\% of 151 patients with chronic sinusitis had middle turbinate concha bullosa, and after resecting the anterior third of the pneumatized turbinate, $80 \%$ of the patients showed improvement in their symptoms. ${ }^{23}$

Also another study by Lam et al on 100 patients with signs and symptoms of chronic sinusitis, spiral CT scan of the paranasal sinuses yielded 47 cases of concha bullosa and a significant relationship between this finding and chronic sinusitis was observed. ${ }^{24}$

Moreover, Massegur et al. reported 4 cases of concha bullosa with chronic sinusitis who underwent endoscopic operation on the middle turbinate, and all the 4 patients were relieved of their symptoms. ${ }^{25}$

our present study correlated with studies of Yahya Basith, K Dua et al., Arslan $\mathrm{H}$ et al., M.H. Baradaranfar which concluded that deviated nasal septum (DNS) was the most common anatomical variation followed by concha bullosa and agger nasi cells, thus further adding to the findings. . $^{18,19,20,21}$

\section{CONCLUSION}

CT plays an important role in the identification of anatomical variations in, and our study reiterates the concept that anatomical variations are important factors in the causation of CRS. CT PNS helps in understanding the complex anatomy of paranasal sinuses which is not possible with plain radiographs. It not only improves the visualization of PNS anatomy but also allows greater accuracy in evaluating PNS disease. In view of the presence of these significant variations, through our study, we would like to emphasize the need for proper assessment in every patient preoperatively, in order to accomplish a safe and effective endoscopic sinus surgery.

\section{REFERENCES}

1. Benninger MS, Ferguson BJ, Hadley JA, Hamilos DJ, Jacobs M, Kennedy DW et al. Adult chronic rhinosinusitis: Definitions, diagnosis, epidemiology \& pathophysiology. Otolaryngol Head and Neck Surg 2003;129(1):S1-32.

2. Benson ML, Oliverio PJ, Zinreich SJ. Nasal and paranasal sinus imaging. J Belge Radiol. 1997;80(2):8991.

3. Lanza DC, Kennedy DW. Adult acute rhinosinusitis defined. Otolaryngology and Head and Neck Surgery.1997;117 (3):S1-7.

4. Lund VJ, Mackay IS. Staging in rhinosinusitus. Rhinology 1993;31(4):183-4.

5. A A Ameri, A Eslambolchi, H. Bakhshandeh.Anatomic variants of paranasal sinuses and chronic Sinusitis. Iran. J. Radiol., June 2005, 2(3,4):121-124.

6. Jiann-Jy Chen, Dem-Lion Chen, Chi-Jen Chen. The Lund-Mackay Score for Adult Head and Neck Computed Tomography. J Radiol Sci 2011; 36 (5): 203208

7. H. Moghaddasi MD,M. Sanei Taheri MD,A.H. Jalali MD,M. Shakiba MD. Correlation of Lund-Mackay and SNOT-20 Before and After Functional Endoscopic Sinus Surgery (FESS): Does the Baseline Data Predict the Response Rate? Iran J Radiol 2009;6(4):207-214.

8. Collet S, Bertrand B, Cornu S, Rombaux P. Is septal deviation a risk factor for chronic sinusitis? Review of literature. Acta Oto-Rhino-Laryngologica Belg 2001; 55 (6): 299-304.

9. Gray L. Deviated nasal septum: incidence and etiology. Ann Otol Rhinol Laryngol 1980; 87 (1): 3-20.

10. Van Der Veken P, Clement P, Buisseret T, Desprechins B, Kaufman L, Derde MP CAT scan study of the prevalence of sinus disorders and anatomical variations in 196 children. Rhinology 1990;28 (3): 177-184.

11. Calhoun KH, Waggenspack GA, Simpson CB, Hokanson JA, Bailey BJ. CT evaluation of the paranasal sinuses in symptomatic and asymptomatic populations. Otolaryngol Head Neck Surg 1991; 104 (5): 480-483.

12. Jones NS, Strobl A, Holland I. A study of the CT finding in 100 patients with rhinosinusitis and 100 controls. Clin Otoloaryngol 1997; 22 (4): 47-51.

13. Yousem DM, Kennedy DW, Rosenberg S. Ostiomeatal complex risk factors for sinusitis: CT evaluation. J Otolaryngol 1991; 20 (1): 419-424.

14. Elahi MM, Frenkiel S, Fageeh N. Paraseptal structural changes and chronic sinus disease in relation to the deviated septum. J Otolaryngol 1997; 26 (1): 236-240.

15. Elahi MM, Frenkiel S. Septal deviation and chronic sinus disease. Am J Rhinol 2000; 14 (6): 175-179.

16. Danese M, Duvoisin B, Agrifolio A, Cherpillod J, Krayenbulh M. Influence of naso-sinusal anatomic variants on recurrent, persistent or chronic sinusitis. $\mathrm{X}$-ray computed tomographic evaluation in 112 patients. J. Radiol 1997;78 (2): 651-657.

17. Lee YU, Suh JD, Youn EK, Kim DH, Lee KJ. Anatomic Variations on PNS CT.J Korean Radiol Soc. 1994;31(3):431-438. 
18. Yahya Basith, Balasubramanian Thiagarajan. Role of anatomical obstruction in the pathogenesis of chronic sinusitis. Otolaryngology online journal. 2012;2 (3).

19. K Dua, H Chopra, AS Khurana, M Munjal. CT scan variations in chronic sinusitis.Indian journal of radiology and imaging. 2005; 15(3): 315-320.

20. Arslan H, Aydinlioglu A, Bozkurt M, Egeli E. Anatomic variations of the paranasal sinuses: CT examination for endoscopic sinus surgery. Auris Nasus Larynx. 1999;26(1):39-48.

21. M. H. Baradaranfar1, M. Labibi. Anatomic variations of paranasal sinuses in patients with chronic sinusitis and their correlation with ct scan staging. Acta Medica Iranica 2007; 45(6): 477-480.

22. Scribano E, Ascenit G. The role of ostemeatal unit anastomis variations in inflammatory disase of the maxillary sinuses. Eur J Radiol. 1997; 24(3): 124 - 127.

23. Nadas S, Duvosini B, Landry N. Choncha Bullosa: ferquency and apperances on $\mathrm{Ct}$ and correlations with sinus diseae in 308 patients with chronic sinusitis. J Head Neck Radiol. 1995; 234- 237.

24. Lom WW, Laing EY. The etiological role of concha bullosa in chronic sinuitis. Eur Radiol. 1996; 6(4): 550 $-552$.

25. Massegur H, Sdema JM. The middle turbinate as the cause of sinusal pathology. Acta - Otorhinolaryngol ESP. 1995; 16(1): 27-29.

26. Mesut S. Tezer, Rauf Tahamiler and Salih. Computed Tomography Findings in Chronic Rhinosinusitis Patients with and without Allergy. Asian Pacific Journal Of Allergy And Immunology 2006; 24: 123-127.

27. M.H. Daghighi, A.Daryani, K. Chavoshi Nejad. Evaluation of anatomical variations of paranasal sinuses. The Internet journal of Otorhinolaryngology. 2007; 7(1): 1-5.

Source of Support: Nil; Conflict of Interest: None

Submitted: 07-07-2019; Accepted: 10-08-2019; Published online: 19-09-2019 